

\section{DISCLAIMER}

This report was prepared as an account of work sponsored by an agency of the United States Government. Neither the United States Government nor any agency Thereof, nor any of their employees, makes any warranty, express or implied, or assumes any legal liability or responsibility for the accuracy, completeness, or usefulness of any information, apparatus, product, or process disclosed, or represents that its use would not infringe privately owned rights. Reference herein to any specific commercial product, process, or service by trade name, trademark, manufacturer, or otherwise does not necessarily constitute or imply its endorsement, recommendation, or favoring by the United States Government or any agency thereof. The views and opinions of authors expressed herein do not necessarily state or reflect those of the United States Government or any agency thereof. 


\section{DISCLAIMER}

Portions of this document may be illegible in electronic image products. Images are produced from the best available original document. 


\section{NOTICE}

This report was prepared as an account of work sponsored by the United States Government. Neither the United States nor the United States Atomic Energy Commission, nor their employees, nor any of their contractors, subcontractors, or their employees, makes any warranty, express or implied, or assumes any legal liability or responsibility for the accuracy, completeness or usefulness of any information, apparatus, product or process disclosed, or represents that its use would not infringe privately-owned rights. 


\title{
Determination of Inorganic Chlorides in tatB
}

\author{
E. Kohn
}

DEVELOPMENT DIVISION

The object of this work is the development of an analytical method for the determination of inorganic chlorides, and primarily ammonium chloride, in TATB produced from TCTNB.

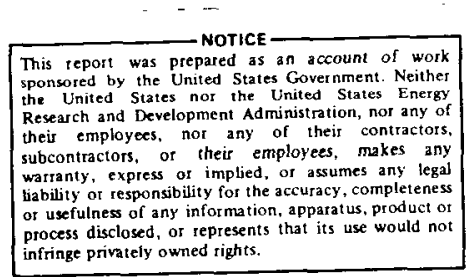

October - December 1974

Endeavor No. 223 


\section{ABSTRACT}

1,3,5-triamino trinitrobenzene (TATB) prepared by the action of ammonia on 1,3,5-trichloro trinitrobenzene (TCTNB) contains a significant amount of inorganic chlorides, particularly ammonium chloride, which are not satisfactorily determined by washing procedures. A method is described herein, which consists of dissolving TATB in concentrated sulfuric acid, purging and collecting the liberated hydrogen chloride in dilute base, and analyzing potentiometrically for chloride ion with an ion-selective electrode.

To ascertain that organic chlorides present in the TATB do not interfere by also producing hydrogen chloride, organic impurities normally found in TATB, were subjected to the same experimental conditions and were found not to yield hydrogen chloride.

A number of TATB samples were analyzed by the technique described and it was found that the chlorine content of these samples was largely of the inorganic type. Because of uncertainties in the presently available method for total chlorides, it was not possible to ascertain the relative proportions of organic and inorganic chlorides in the samples examined.

\section{DISCUSSION}

Trace analysis of chlorine in TATB is routinely conducted by combustion of the sample in a Parr bomb and analytical determination of chloride ion by potentiometric titration employing an ion-selective electrode(1). Chlorine containing impurities in the bulk-produced TATB are believed to be of two types: (1) organic chlorides, primarily compounds with chlorine atoms on the aromatic ring and (2) inorganic chlorides, primarily ammionium chtoride.

Chlorine on the aromatic ring is relatively unreactive, and since those compounds are fairly non-volatile, they are not particularly objectionable impurities in high explosive compositions. Ammonium chloride, on the contrary, is somewhat volatile and capable of decomposition to form hydrogen chloride and ammonia, which in turn may react with weapons components. The assay of inorganic chlorides and more specifically ammonium chloride in a TATB sample is therefore of considerable interest and importance, and methods were sought for its determination.

Extraction techniques which have been previously investigated $(2,3)$ do not yield the full inorganic chloride value of a sample, since much of the ammonium chloride is deeply embedded in the TATB crystals and is not readily leached. Photomicrographs taken with the Scanning Electron Microscope (SEM) show $(4,5)$ that most raw TATB crystals have profusely pitted surfaces, which are attributed to originally occluded ammonium chloride particles which were leached by the aqueous washing that is 
routinely performed in the workup of freshly prepared TATB. Ammonium chloride particles which were completely occluded in the TATB crystals are not removed by the washing. In contrast to raw TATB, particles recrystallized from sulfuric acid exhibit no such pits.

In order to facilitate total removal of ammonium chloride and other inorganic chlorides from the sample and their precise analysis, a method was developed which consists of dissolving the raw TATB in concentrated sulfuric acid and purging the hydrogen chloride liberated by the reaction

$$
2 \mathrm{NH}_{2} \mathrm{Cl}+\mathrm{H}_{2} \mathrm{SO}_{4} \longrightarrow\left(\mathrm{NH}_{4}\right)_{2} \mathrm{SO}_{4}+2 \mathrm{HCl}
$$

into a collecting flask for chloride ion assay. Details of the method are presented in the EXPERIMENTAL Section.

Since the samples were known to contain some organic chlorides as well, it had to be ascertained that such compounds do not yield hydrogen chloride under the conditions of the experiment. Two blank runs were therefore conducted in which a small amount of such chlorinated aromatic compounds was used in place of the TATB. In one case the blank was TCTNB containing a large amount of 1,2,3,5-tetrachlorodinitrobenzene. In the other case the blank was the solid residue from the evaporation of amination solvent used in the production of TATB. This material contained all the organic impurities normally extracted from raw TATB $(6)$. In each case hydrogen chloride was not detected.

Table I summarizes the results for the inorganic chloride method on runs thus far performed, and also lists the corresponding values for total chlorides determined by the Parr bomb method, and by the basic hydrolysis method, as available. It will be noted that the chloride ion assays by the present method are nearly as great and occasionally greater than those from the Parr method. Since the results from the hydrolysis are also always greater than from the Parr method it is believed the Parr method produces results which are low by as much as $15 \%$, the error being greater at the higher chlorine content(7).

Standard deviations are given in the table for those cases in which multiple analyses were performed. These range from 0.002 to 0.016 with a probable deviation of less than 0.01 . Principal errors in the method are loss of hydrogen chloride in the reaction train through leaks at the stopper or tubing connections and uncertainty of the titration endpoint. The latter error is expected to be confined to the third decimal point of the chloride content, and the former is an unsymmetrical error and can only yield low results.

Because of uncertainty of the total chlorine value in TATB from the Parr method, the feasibility of obtaining such a value from the sulfuric acid purging technique was investigated. In a number of runs, after all removable hydrogen chloride was collected at ambient conditions, the temperature of the solution was raised to $100-120 \mathrm{C}$ and the nitrogen purge was continued for one to three hours. In all such cases, additional 
Table I. Chlorine Analyses in TATB by the Inorganic Chloride Method and Comparable Data by Other Methods

\begin{tabular}{|c|c|c|c|c|c|}
\hline Sample No. & $\begin{array}{l}\text { Inorganic } \\
\% \mathrm{Cl} \\
\end{array}$ & Average & $\underline{\sigma}$ & $\begin{array}{l}\text { Parr } \\
\% \mathrm{Cl}\end{array}$ & $\begin{array}{l}\mathrm{NaOH}{ }^{*} \\
\% \mathrm{Cl} \\
\end{array}$ \\
\hline $4128-16-01$ & 0.372 & & & 0.37 & \\
\hline $4128-16-01$ & 0.385 & 0.378 & 0.009 & 0.37 & \\
\hline $4267-16-01$ & 0.882 & & & 0.85 & 0.93 \\
\hline $4267-16-01$ & 0.854 & & & 0.85 & 0.93 \\
\hline $4267-16-01$ & 0.882 & 0.873 & 0.016 & 0.85 & 0.93 \\
\hline $4324-16-01$ & 0.685 & & & 0.65 & \\
\hline $4350-16-A$ & 0.304 & & & 0.38 & \\
\hline $4350-16-B$ & 1.604 & & & 1.42 & \\
\hline $4353-16-02$ & 0.160 & & & 0.19 & 0.17 \\
\hline $4353-16-02$ & 0.162 & & & 0.19 & 0.17 \\
\hline $4353-16-02$ & 0.158 & 0.159 & 0.002 & 0.19 & 0.17 \\
\hline $4352-16-02$ & 0.563 & & & 0.45 & 0.54 \\
\hline $4352-16-02$ & 0.548 & & & 0.45 & 0.54 \\
\hline $4352-16-02$ & 0.561 & 0.557 & 0.008 & 0.45 & 0.54 \\
\hline $4353-16-01$ & 0.551 & & & 0.50 & 0.61 \\
\hline $4353-16-01$ & 0.553 & & & 0.50 & 0.61 \\
\hline $4353-16-01$ & 0.558 & 0.554 & 0.004 & 0.50 & 0.61 \\
\hline
\end{tabular}


amounts of hydrogen chloride were collected, amounting to approximately $5 \%$ of the total chlorides assayed. In control runs however, employing aromatic chlorides described previously to be present in the TATB, quantitative recovery of chlorine could not be achieved. Such aromatic chlorides are apparently quite stable in hot concentrated sulfuric acid and would require stronger oxidizing conditions for their decomposition and the consequent liberation of hydrogen chloride or chlorine.

\section{EXPER IMENTAL}

The apparatus for the inorganic chloride analysis in TATB is schematically given in Fig. 1. The reaction train consisted of a cylinder of commercial dry nitrogen, a gas regulator with needle valve, the reaction flask, a gas washing bottle and a small rotoflowmeter. Details of the reaction flask are shown in Fig. 2. It consisted of a 50 me graduated Erlenmeyer flask with a $\$ 19 / 38$ ground glass joint. The glass bubble tube which reached half way down the flask was extended by a piece of polyethylene tubing which stretched to the very bottom of the flask. The reaction vessel was so constructed as to minimize gas space above the solution from which the hydrogen chloride had to be purged. Because the polyethylene tubing was pliable it did not interefere with the rapid action of the magnetic stirring bar. The gas washing bottle was of 125 me capacity, was equipped with a fritted disc of coarse porosity and was filled with about $80 \mathrm{ml}$ of very dilute sodium hydroxide solution.

The procedure consisted of weighing $5 \mathrm{~g}$ of the TATB sample (to the nearest $\mathrm{mg}$ ) into the reaction flask, adding 40 me of concentrated sulfuric acid (commercial grade) and quickly connecting the train as shown in Fig. 1. Nitrogen bubbling was then commenced through the train at a rate of approximately $150 \mathrm{ml} / \mathrm{min}$ for one hour. Upon agitation by the magnetic stirring bar the slurry turned into a clear, light amber solution in a period of 5-10 minutes. After the one hour purge the collecting bottle was replaced with a fresh one and the bubbling was continued for another hour. The contents of each collecting bottle were then quantitatively transferred for potentiometric analysis of chioride ion. The assay of the second bottle was never greater than $5 \%$ that of the first bottle; the final chlorine value reported was the sum of the assays of both bottles. In several of the initial experiments a third purging was carried out to assure completeness of recovery of hydrogen chloride; no chlorine was detected in such instances. The experiments at the higher temperature were conducted in a like manner, except that the reaction flask was placed in an oil bath which was heated to about $120 \mathrm{C}$.

Three control experiments were performed. In one, the entire procedure was carried out as above except that the sample was omitted. No significant amount of chlorine was detected (less than $0.0003 \%$ ). In another control experiment, the TATB normally used was replaced by $0.10 \mathrm{~g}$ of a mixture of TCTNB $(85.5$ wt \%), 1,2,3,5-tetrachlorodinitrobenzene (12.2 wt \%), 


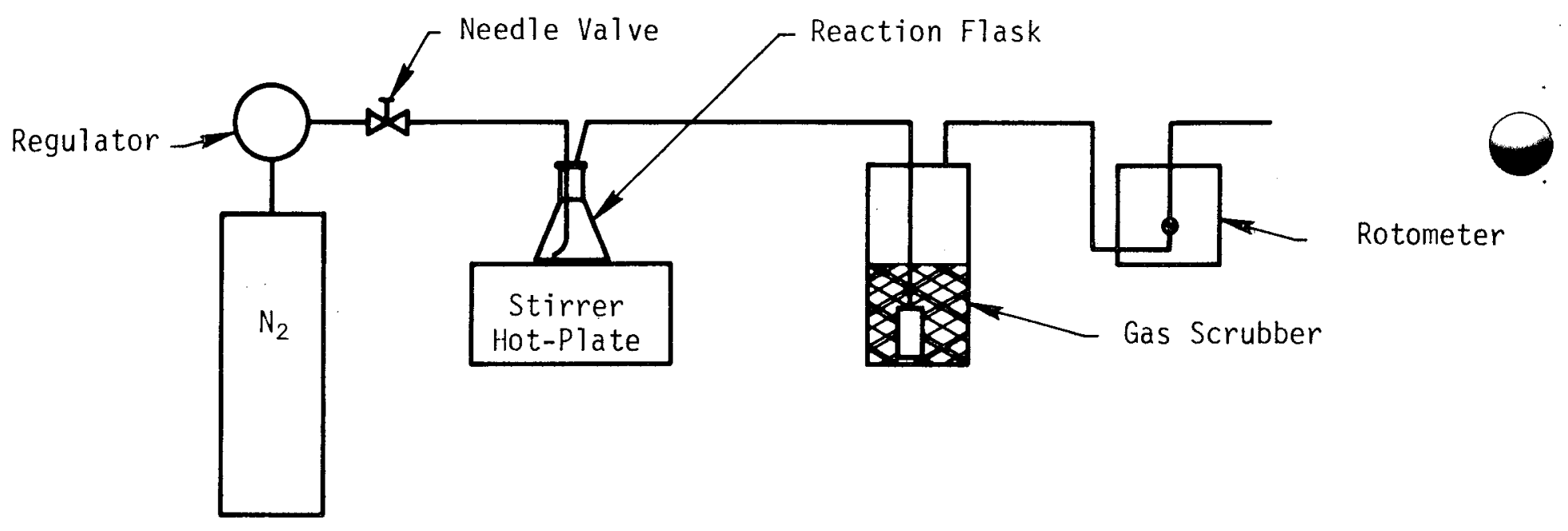

Fig. 1. Reaction Train

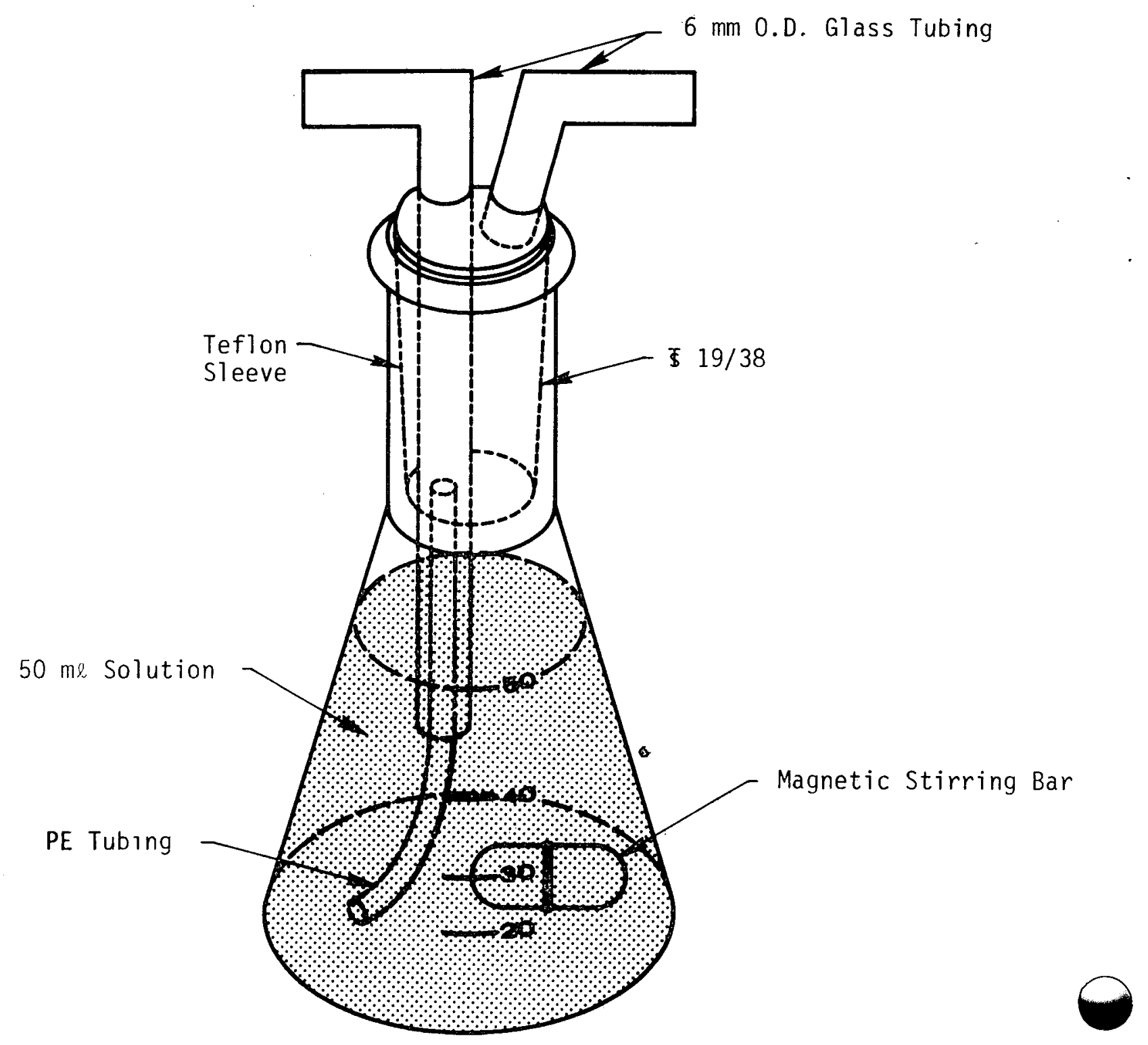

Fig. 2. Reaction Flask 
and 1,3,5-trichlorodinitrobenzene $(2.0 \mathrm{wt} \%)(8)$, and the procedure was performed as described previously (at room temperature). In this case also no significant amount of chlorine was detected. In a third control experiment, the normally used TATB was replaced by $0.10 \mathrm{~g}$ of a solid sample prepared by evaporating water washed toluene solvent obtained from the amination reaction of 1,3,5-trichloro trinitrobenzene (from which the solid TATB had been removed). This material was composed of the organic impurities normally extracted from TATB, in roughly the same proportions $(6)$. Again chlorine was not detected.

The mixture of the second control experiment was, subsequent to the initial analysis, carried out at room temperature, subjected to a temperature of $100-120 \mathrm{C}$ and liberated hydrogen chloride was assayed after each of two successive one hour purgings with nitrogen. In each case approximately $2.5 \%$ of the total chlorine in the sample was detected. Furthermore, a small amount of sample was observed to have sublimed out of the reaction vessel. The results indicate that the elevated temperature purging is not suitable as an analytical method for total chlorides in TATB.

\section{CONCLUSIONS}

The method described in this report for the analysis of inorganic chlorides in TATB, which consists of dissolving the sample in concentrated sulfuric acid, purging the liberated hydrogen chloride from the reaction flask, and analyzing for chloride ion, was found to be an unequivocal technique for the evaluation of inorganic chloride content in TATB. The method has satisfactory precision and probably also accuracy. Inorganic chloride (primarily ammonium chloride) content of the several samples analyzed was found to be very high in proportion to other chlorides (aromatic chlorine compounds), though the exact proportion of the two types could not be ascertained in each case. While previous methods have yielded results suggesting about equal amounts of inorganic and organic chlorides, the method here reported suggests an about fourfold excess of inorganic chlorides over organic chlorine in the samples analyzed.

\section{FUTURE AND RELATED WORK}

The construction of several reaction trains is now underway. These will permit the simultaneous determination of multiple samples with $3-5$ analyses available from an 8-hour workday. A detailed procedure will be written which will permit the performance of the method on a routine basis.

A number of parallel or related analytical techniques are presently under investigation or are planned. Initial efforts on the alkaline hydrolysis method to yield total chloride in TATB have been reported elsewhere(7). A method for ammonium ion analysis has shown initial 
promise and is being investigated $(9)$. In this technique, the TATB sample is dissolved in sulfuric acid and the intensity of the $\mathrm{NH}_{4}^{+}$proton signals is determined by nuclear magnetic resonance spectroscopy. Some work is also in progress on a differential infrared method, in which the $\mathrm{NH}_{4}^{+}$absorption of the sample in a $\mathrm{KBr}$ disc is compared to the background absorption of a TATB sample recrystallized from sulfuric acid, in a reference $\mathrm{KBr}$ disc. It is also planned to investigate the analysis of TATB for total chlorine by an X-ray fluorescence method.

Since chloride ion is effectively removed from TATB by dissolving it in sulfuric acid and purging the solution, the recrystallizion of TATB from sulfuric acid is being investigated as a means of producing ammonium chloride free material. 


\section{REFERENCES}

1. Method developed by Dr. B.D. Faubion, based on a technique in Kolthoff, Sande11, Meehan and Bruckenstein, "Quantitative Chemical Analysis," 4th Ed., the Macmillan Co., 1969, p. 586, and a procedure described by G. F. Mortenson in his memo of $4 / 3 / 72$ to A. Popolato.

2. Results of aqueous digestion studies of TATB by J. Sandoval in TATB Process Reports, Pantex, MHSMP-74-35 and MHSMP-75-5.

3. TATB grinding and aqueous digestion, W. Selig, private communication of $7 / 24 / 1974$.

4. SEM photomicrographs of raw TATB taken by R. Meisenheimer, courtesy of J. Humphrey.

5. SEM photomicrographs of raw TATB and TATB recrystallized from sulfuric acid, taken in this laboratory and to be reported elsewhere.

6. The compounds were identified by thin Tayer chromatography by C. Schaffer according to the method of S. Yasuda, J. Chromatogr. 71, 481 (1972).

7. Alkaline hydrolysis method for total chlorine in TATB described by Dr. B. D. Faubion, Chemical Analyses of TATB report, Pantex, MHSMP-75-5.

8. Liquid chromatographic analys is performed by $C$. Schaffer.

9. Private communication, G. Clink. 